ALPHA Nº 29 Diciembre 2009 (9-22)

ISSN 0716-4254

http://alpha.ulagos.cl

\title{
ESCRITURAS DE “ENCANTO” Y PARLAMENTO EN LA POESÍA HUILLICHE ${ }^{1}$
}

\author{
Tales of "charm" and parliament in Huilliche poetry
}

\section{Pilar Álvarez-Santullano* Eduardo Barraza J.**}

\section{Resumen}

En la tradición oral huilliche, los "relatos de encanto" configuran un espacio sagrado, regidos por una intemporalidad y localizados geográficamente. Allí habitan antepasados en simbiosis con la naturaleza. Juntos, naturaleza y antepasados, constituyen un reducto natural que dialoga con el hombre huilliche. El encanto es un espacio que habla y esta condición es recogida por la poesía huilliche. En cuanto al "parlamento" - en tanto "palabra empeñada o comprometida en ceremonial público entre el bando español y el bando mapuche - éste ha sido una de las formas discursivas al servicio de la dominación en las que predomina la palabra hegemónica del conquistador, sin que se aprecie la voz del indígena que entra en el acuerdo pactado. La poesía huilliche reescribe y actualiza esas prácticas histórico-sociales -y otras de carácter historiográfico - según se puede apreciar en un texto como "Parlamento de Huenteao en la Isla Pucatrihue" de Jaime Huenun, según se analiza en este artículo.

Palabras clave: Poesía huilliche, etnoliteratura, discurso de la conquista.

\begin{abstract}
In oral huilliche tradition, the tales of charm configure a sacred space, ruled by an atemporality and geographically localized. There, the ancestors live in simbiosis with nature. Together, nature and ancestors, constitute a natural redoubt which dialogues with the huilliche people. Charm is a space that speaks and this condition is taken up by hulliche poetry. As for parliament —as the word pledged or committed in public ceremony between Spanish and Mapuche parties - this has been one of the discursive forms at the service of domination where the hegemonic word of the conqueror predominates, without the indigenous voice being apreciable in the pact that is reached. Huilliche poetry rewrites over those socio-historical practices, over these - and others more of historiographic character - and it updates them in a text like "Parlamento de Huenteao en la Isla Pucatrihue" by J. Huenun, as we analyze in this article.
\end{abstract}

Key words: Huilliche poetry, etnoliterature, discours of the conquest.

\footnotetext{
${ }^{1}$ Este artículo forma parte del proyecto Fondecyt No 1085317 (2008-2010): “El discurso de la conquista: una serie textual autónoma de la literatura chilena”.
} 
En su matriz oral, el relato de "encanto" huilliche se configura en torno a un espacio sagrado, geográficamente localizado, donde el tiempo no transcurre (illo tempore) habitado por antepasados o kuifikeche en simbiosis con la naturaleza. Naturaleza y kuifikeche constituyen un reducto natural que dialoga con el hombre huilliche. El "encanto" es espacio que habla, ya sea a través de quienes lo habitan o porque la naturaleza misma actúa enviando señales que deben ser interpretadas. Es así como estos espacios de encanto pueden volverse inaccesibles al hombre mapuche en determinadas circunstancias, lo que se percibe como señal de que el comportamiento humano no está siendo el adecuado respecto de los códigos del küme mogen o normas del buen vivir huilliche. Esta dimensión potencialmente dialógica del espacioencanto, retomada en la poesía de Huenun a través de la modalidad de un "parlamento" pronunciado por Huenteao, constituye nuestro punto de partida para el análisis presentado aquí (ver anexo). ${ }^{2}$

En el contexto literario, el término parlamento refiere a la intervención de un personaje, ya sea como parte de un diálogo — para hablar con otro(s) o como monólogo, modalidad de enunciación esta última en que el personaje da curso a sus cavilaciones sin dirigirse a nadie en particular. Por otra parte, en un contexto historiográfico, parlamento remite en Chile, y especialmente en situaciones de relaciones interétnicas, a un ceremonial público en el cual se pactan y norman ${ }^{3}$ acuerdos de paz de mutua conveniencia, en un primer momento, entre mapuches y españoles y, más tarde, una vez establecida la República, entre mapuches y chilenos. Tales acuerdos, una vez transados y puestos por escrito, se revelan como una de las formas discursivas de la dominación en las que predomina la voz del conquistador que subordina la voz del indígena incluida en el acuerdo pactado.

La poesía huilliche actual no sólo reescribe sobre esas prácticas histórico-sociales, sino que, además, en el texto "Parlamento de Huenteao en la Isla Pucatrihue” de Jaime Huenun, las actualiza como situación de enunciación monológica contraviniendo con ello lo esperado en los encuentros de ambos bandos en los históricos parlamentos o de quien — según la tradición oral- debe hablar a su pueblo para guiarlo.

El "Parlamento de Huenteao en la Isla de Pucatrihue" preside significativamente la sección "Ceremonias del regreso" del libro de Huenun. El texto - anunciado como "parlamento"- abre resonancias de otros discursos propios de las “ceremonias” políticas entre fuerzas beligerantes que transaban

2 Jaime Huenun "Parlamento de Huenteao en la Isla Pucatrihue”, en Ceremonias. Santiago: Universidad de Santiago, 1999:43. Citaremos por esta edición.

${ }^{3}$ Leonardo León. “El parlamento de Tapihue, 1774”, en Nütram Año IX. NNo 32, 1993/Santiago: Rehue, 7. Citaremos por esta edición. 
la paz entre las autoridades coloniales, republicanas y los jefes mapuches, consolidando las relaciones de poder de unos en desmedro de los otros. El título, que incluye la localización de enunciación del parlamento, se asemeja parcialmente a las denominaciones que recibieron estos actos públicos durante los períodos de la Conquista, la Colonia y la República, ${ }^{4}$ celebrados entre "hombres que en esos momentos detentaban el poder" (León, 1993:8). Cada "parlamento" remite a la datación de acuerdos de paz y de convivencia celebrados en un lugar que alcanzara relevancia histórica y geográfica.

Sin embargo, tal contextualidad historiográfica y temporal queda, directamente desplazada en el texto de Huenun, en favor de la re-escritura de un discurso de "encanto" compuesto por cuatro enunciados —al modo de soliloquios - que pronuncia ahora Huenteao respecto de sí mismo, como entidad sagrada y venerada y con respecto a lo que ha ocurrido con su pueblo. El parlamento como espacio de habla público, propicio para la negociación y consecuente formulación de un Tratado, ha sido desplazado por el parlamento de la soledad, del habla íntima, mediante la cual Huenteao acusa su situación actual y la miseria e ingenuidad de su pueblo. Por lo mismo, en este parlamento está ausente la fuerza contraria de antaño y el bando winka queda reducido en su calidad de interlocutor. De hecho, la decodificación en nota al pie de página que hace Huenun, posterga cualquier referencia a un parlamento histórico. Desde el comienzo se presenta a Huenteao como ser marino, ser encantado como "piedra viviente" en medio de un roquedal de Pucatrihue, ${ }^{5}$ sector costero al oeste de Osorno, hacia donde peregrinan las comunidades huilliches-lafquenches con sus bandas —en días de Gillatun - a dejarle comida y otros obsequios y a pedirle permiso para hacer la ceremonia donde rogarán por buenas cosechas y otros beneficios.

Este espíritu sagrado es quien habla o pronuncia su "parlamento" situado en un espacio propio, la "Isla de Pucatrihue", escenario propicio para la renovada puesta en escena de los parlamentos tradicionales. ${ }^{6}$ Sólo que el texto reproduce parcialmente la escena político-militar de antaño. Huenteao profiere un discurso a la manera de un soliloquio, como hablando consigo

\footnotetext{
${ }^{4}$ Así como hubo sucesivos parlamentos en Quilín (1641) Tapihue (1774-1825) Lonquilemo (1784) Negrete (1803) para el pueblo huilliche, el Parlamento de las Canoas, pactado en 1793 con Ambrosio O’Higgins, y el Parlamento de Coz-Coz (18 de enero de 1907) celebrado internamente por el propio pueblo huilliche, revisten gran importancia.

${ }^{5}$ Pucatrihue, actual balneario y caleta de pescadores situada en la Costa de la X Región. Voz cuyo significado es "Lugar compuesto de cortes", compuesto por la partícula pluralizadora pu, katxi "cortado" y we "lugar".

${ }^{6}$ El hecho de que en la tradición oral se asegure que Huenteao permanece en la Isla con su ejército (como parte de éste se suele mencionar al Sargento Millalikan) da cuenta del simbolismo militar que incluye, también, el encanto.
} 


\section{Pilar Álvarez-Santullano - Eduardo Barraza}

mismo ante un escenario sin público: "hablo sólo bajo el cielo del amanecer" nos dice. Por esta vía, asistimos al "simulacro" de una puesta en escena tipificada en la memoria colectiva huilliche y en la historia híbrida de mapuches, españoles y criollos. Como escenario, la "Isla" de Huenteao es el eje que dimidia los espacios del mar y de la tierra tal como un orador de uno de los pueblos que participa en los "parlamentos".

En los relatos de tradición oral sobre Huenteao hay diversas variantes acerca de cómo éste llega al mar. En algunas versiones llega joven y, en otras, siendo ya un hombre mayor. Según la más difundida, el anciano se aleja del hogar donde vivía con su hijo, debido a acusaciones de acoso sexual que su nuera habría formulado contra él. ${ }^{7}$ Huenteao se dirige hacia el mar, donde vaga durante unos días hasta desaparecer. En algunas versiones se lo ve con una mujer de larga cabellera antes de encantarse, lo que hace suponer un posible matrimonio. En los relatos tradicionales este vínculo entre mapuches con un habitante de las aguas era bien visto porque los miembros pertenecían a distintos lof o linajes, lo que por una parte regulaba el incesto y, por otra, generaba una alianza mediante la cual la comunidad que cedía a uno de sus miembros en matrimonio era beneficiada con los productos del mar. En el relato actual de Huenteao aparece muy difuso el vínculo matrimonial. El encanto se privilegia más bien como fuente de recursos para la comunidad, pero ya no como mafün o pago matrimonial, sino como parte de la protección que Huenteao brinda al pueblo huilliche a través de un pacto de mutua conveniencia, ya que el encanto es fuente de abundancia de alimentos para la comunidad a la vez que recibe ofrendas de ésta. Como resultado, naturaleza (roquerío) y kuifikeche ${ }^{8}$ - representados por Huenteao-constituyen un reducto natural que dialoga con el hombre huilliche orientando su forma de vida, vigilando el curso de la vida de los hombres, de la naturaleza y de los bienes del mar. Pero este pedestal en el cual se sitúa Huenteao es, a la vez, una suerte de prisión. No puede moverse del sitio del "encanto", ya que mediante esta forma de encierro se establece la comunicación entre el ser "encanto" y el

\footnotetext{
${ }^{7}$ Hasta aquí, el relato de Huenteao se asemeja a los relatos o epeo de Sumpall y del joven Manquián, habituales en los grupos mapuches ubicados más al norte de los huilliches. Sin embargo, el simbolismo actual de la transformación de Huenteao — presente también en el resto del conjunto de relatos de encanto huilliche - se activa a partir de las directrices que desde el texto se generan para el modo de vida del hombre huilliche, lo que vendría a superar (en el sentido de agregar algo más) la interpretación propuesta para los relatos mapuches no huilliches, cuyo eje central estaría en la regulación del incesto.

${ }^{8}$ Huenteao es uno de los kuifikeche (kuyfi "antiguo", che "persona”, a lo que se agrega la partícula pluralizadora $k e$, es decir "antepasados”) que habita en las rocas, aunque los demás — si bien son invocados en el gillatun — no suelen manifestarse como el anciano Huenteao.
} 
mundo huilliche, comunicación que se elimina cuando alguna de las partes no cumple con el ritual o con los respectivos roles que exige el ceremonial.

Aunque en la estructura profunda del discurso oral sobre Huenteao se revierte la acusación de que es objeto, pues alcanza una condición superior de "encanto", el "peso de la piedra en que lo han convertido" sus paisanos hacen de él —en el texto de Huenun - un sujeto de tragedia, una especie de nuevo Prometeo que no puede moverse de su sitio, siendo, a la vez, un "ser encanto que habla" - un ser sagrado- y un "monumento pétreo" — prosaico y material - apto para nidales y guaneras de gaviotas.

En la tradición y solemnidad pública del "parlamento" se hacía oír la voz de los líderes de cada bando, previamente identificados y calificados como “dignatarios y sujetos de distinción” (León, 10) los del bando español y "caciques mapuches” jerarquizados y distribuidos equitativamente conforme a la calidad de las comunidades que representan y al número de capitanejos y mocetones que los acompañan (León 12-16).

En el texto de Huenun que analizamos, Huenteao se presenta a partir de un acto de habla personal, en conformidad al rango protocolar que le corresponde como sujeto superior, como ser "encanto" de la comunidad huilliche, de quien se espera un solemne discurso: "Si he de decir algo... diré" ...Sin embargo, este decir no reproduce la majestad dialógica de los parlamentos de la conquista y de la Colonia en que se transa la paz, el canje de prisioneros, las alianzas y obligaciones mutuas, el comercio, la evangelización, el intercambio de tributos y agasajos. Pero este soliloquio no es un mero recurso de la retórica teatral en la cual se finge que se habla ante un escenario vacío. Del escenario de Pucatrihue ha desaparecido la contraparte española (o chilena, si corresponde) y el público que contempla Huenteao no responde al imaginario belicoso de la "larga y envejecida guerra de Arauco" como la califica un autor anónimo. ${ }^{9}$

"Los hombres que ahora veo se hincan en la arena agotados por el viaje y la memoria”, describe Huenteao. En el "aquí" y "ahora” del ser "encanto", estos hombres no son los del pasado solemne que propiciaba la comunicación y convivencia con los seres de "encanto" como Huenteao. Los huilliches no aparecen erguidos sino inclinados. No "de gestos robustos" — como los describió Ercilla - sino “agotados” luego del tránsito por el espacio y el tiempo de la memoria colectiva que ya no procrea ni cobija el mito ni lo sagrado. "La fuerza de su sangre ha quedado en el camino”, es la exégesis de Huenteao, lo cual indica que el mito no pervive sino que ha caído en el decurso de una memoria frágil que no lo sustenta sino que lo envejece.

${ }^{9}$ Remitimos a La guerra de Chile. Edición crítica de Mario Ferreccio y Raissa Kordic. Santiago: Biblioteca Antigua Chilena, 1986. 


\section{Pilar Álvarez-Santullano - Eduardo Barraza}

Es así como esta secuencia del "parlamento" de Huenteao proporciona las claves de la ruptura entre la voz del más importante kuyfikeche y su pueblo, entre el mito y la historia, entre la historia y el admapu (tradición). El nexo entre ellos era la lengua común, la palabra no mediada por "lenguaraces" ni "ladinos", intérpretes nativos que aprendían la lengua ajena, la de Castilla, transando la propia que circulaba como traslapada, como mediación, simulación de canje y traducción de la lengua propia, el mapuche o mapuzugun, tempranamente hibridado por la lengua del conquistador. Y en ese canje la lengua propia se ha ido agotando — “deshilachando”, percibe Huenteaoperdiendo su integridad. Ya no es ese "idioma” tratable y compartido originariamente, sino los vestigios, ahora apenas perceptibles en fórmulas fosilizadas, palabras sueltas y enunciados castellanizados de la lengua, todo en el contexto de interlengua que afecta al chezugun ${ }^{10}$ desde donde han operado una serie de mecanismos de inhibición, sanción social y de de-solidaridad que actuaron en detrimento de la vitalidad del habla huilliche, mecanismos que se enmarcaron en políticas fuertemente colonizadoras, cuya funcionalidad se ha centrado en la extirpación de las culturas locales y el borramiento ontológico del otro, particularmente a través del acallamiento de la lengua, todo lo cual provoca lo que Mignolo denomina "la herida colonial", el sentimiento de inferioridad impuesto en los seres humanos que no encajan en el modelo" de los relatos y de la lengua del conquistador. ${ }^{11}$ El asunto lingüístico es tema que la dirigencia huilliche ha enfatizado históricamente a través de documentos ${ }^{12}$

\footnotetext{
${ }^{10}$ Desde nuestros primeros estudios sobre la lengua mapuche, señalamos que la variedad huilliche era nombrada en San Juan de La Costa como chezugun. En esta época, a veces usamos la transcripción más cercana a la fonética tsesungun, otras veces, siguiendo el alfabeto unificado usamos chesungun o chedungun según variantes que alternan en los hablantes. Actualmente, usamos chezugun siguiendo el alfabeto Azümchefe, esfuerzo reciente de normalización grafemaria de la Corporación Nacional de Desarrollo Indígena (CONADI).

11 “La colonización del ser consiste nada menos que en generar la idea de que ciertos pueblos no forman parte de la historia, de que no son seres. Así, enterrados bajo la historia europea del descubrimiento están las historias, las experiencias y los relatos conceptuales silenciados de los que quedaron fuera de la categoría de seres humanos, de actores históricos y de entes racionales"... Se llegó al "establecimiento de una matriz colonial de poder, a dejar a determinados pueblos fuera de la historia para justificar la violencia en nombre de la evangelización, la civilización” (Mignolo, 2007:30).

${ }^{12}$ En los memoriales se reclama el derecho a la enseñanza de la lengua mapuche y el derecho a hablar en lengua propia. Estos reclamos en favor de la instrucción en lengua mapuche forman parte del derecho al reconocimiento; intento de revertir la negación ontológica comportada en el silencio de la lengua en la que se funda, se dice y se reconoce el ser mapuche. Según un Memorial de 1936 "los particulares extranjeros y nacionales dicen que no hay indios-mapuches con el fin exclusivo de quitarnos nuestras tierras”. La interpelación que exige la enseñanza del idioma mapuche (que más tarde será retomada por la dirigencia actual) se extiende en este Memorial hacia la sociedad mestiza, por cuanto la lengua mapuche es "el idioma nativo de los padres de la raza chilena” y es portadora de "la civilización incaica del inca Atahualpa; que es
} 


\section{Escrituras de "encanto" y parlamento en la Poesía Huilliche}

en los que se reitera la relación entre lengua y sobrevivencia del colectivo, entre lengua y continuidad histórica del grupo.

Como en el Popol Vuh, los dioses necesitan ser alabados, que sus fieles digan sus nombres. Los hombres de Huenteao que en este hoy traen de regreso el ceremonial del vínculo entre el hombre y los seres protectores, sólo pueden dirigirle retazos, "hilachas" de un idioma antes compartido. La separación lengua-hombre lleva consigo la separación de la comunión que impera entre el hombre y Huenteao, de modo que éste no puede atender a los ruegos de esos súbditos "viejos y temerosos" que acuden a él. En esta versión de Huenun, el personaje "encanto" muestra su revés, su "des-encanto", renuncia a un poder que antes poseía a raíz de la ausencia de la lengua y del hombre que debe hablarla, por la pérdida de la perennidad del mito. "Se entregan a un poder que nunca tuve”, confiesa Huenteao en su soliloquio, privado e íntimo, ajeno a la voz pública, colectiva y enmascarante que primaba en los "parlamentos" coloniales donde se pactaban promesas que ninguno de los bandos pensaba cumplir, como evalúa en 1870, Máximo Ramón Lira en su novela $A$ orillas del Bío-Bío. ${ }^{13}$

Como toda fiesta ritual, el ceremonial del homenaje al ser "encanto" concluye una vez efectuada la peregrinación, el ruego, la ofrenda. Y he aquí, que llegados a esta instancia, Huenteao ratifica su condición desacralizada y la desacralización del rito y de sus oficiantes. Desnuda de encantamiento, la mirada de Huenteao no concede ningún privilegio sacrosanto a las ofrendas: “el pan y el tabaco", el "trigo y las flores” que le regalan serán alimento de las olas y de las profundidades, sin más, y el fruto del ritual será una "ración pobre”, magra, escasa. No hay una retribución dadivosa del ser encanto, ni un rico intercambio de presentes y banquetes como ocurría en los parlamentos históricos (Villalobos, 1982).

más moral que la civilización europea”, con lo que se reconoce en la lengua un valioso sustrato originario de la nación, legitimándose su derecho a ser valorada por su pre-existencia y carácter pancultural que la vincula con el Imperio Inca. Cfr. Pilar Álvarez-Santullano B. y Amílcar Forno S. "La inserción de la lengua mapuche en el currículum de escuelas con educación intercultural: un problema más que metodológico" en Alpha $\mathrm{N}^{\circ} 26$ (julio 2008):9-28.

13 "Después de muchos años de cruda guerra, después de innumerables combates en que por una parte i otra se había luchado con heroísmo sin igual, las hostilidades habían determinado por medio de un parlamento, especie de tratado que los jefes de los españoles y los jefes araucanos habían ajustado con poquísima buena fé. Esto sin embargo, no obstaba para que los indios, manifestando la mayor confianza, acudiesen a los fuertes y a las ciudades españolas, atraídos unos por la curiosidad, por el interés otros, algunos especialmente los jefes, por el deseo de disfrutar durante la paz de las comodidades de la vida cotidiana”. Máximo R. Lira.

A orillas del Bío-Bío. (Escenas de la vida araucana). Santiago: Imprenta Independiente (1870):3-4. 
Huenteao clausura su parlamento solitario ratificando la ruptura de la alianza inmemorial entre el hombre y sus antepasados representados por el "anciano-encanto". "El turbio remolino de los tiempos nos aparta nuevamente", dice Huenteao, como una apelación a que tal alianza pudiese ser renovada, puesto que el ser "encanto" no renuncia a una condición sincrética, propia de la divinidad: Huenteao se sabe piedra, roca visible y roca invisible; piedra que habla y piedra que calla. Huenteao no aparece detenido en la juventud - 0 en la plenitud del ser "encanto"- sino en "una vejez eterna" que no avanza ni retrocede. En medio de una vida ya vivida larga-mente y a la espera de la muerte que no llega y que eterniza trágicamente la vejez. En síntesis, Huenteao deviene en un Ser "encanto" ya anciano, carente de la esencia del ser "encanto" que más que presidir un ritual está condenado a fingirlo sin creer en él ni en los oficiantes. Su solitario parlamento — "bajo el cielo del amanecer" - es un hablar al que sólo responde el propio eco de su voz vencida, no una voz como la que se disputaba y vibraba en los "parlamentos" de la conquista que, sin embargo, ya llevaba consigo el vencimiento del subalterno, citado a un pacto del que sólo percibía "hilachas" de la lengua de Castilla, habla conquistadora, también, que terminará subordinando la lengua de la tierra que no podía competir con las seis lenguas imperiales de la europa del siglo XVI (Mignolo, 2007).

Como escenario, la "Isla" de Huenteao es un eje que comunica los espacios del mar y de la tierra. Pero Huenteao ya no es mediador entre los seres del mar y sus peticionarios costeros. "El turbio remolino de los tiempos" que llega hasta la actualidad separa al "ser encanto" de los hombres y Huenteao se queda sin interlocutores a quienes dirigir la palabra y sólo oye su propia voz mientras amanece en la Isla.

La reclusión de Huenteao actualiza una intercomunicación entre el ser “encanto” y los hombres, el corte del tránsito entre la tierra y el roquerío se interpreta como discurso regulatorio del modo de estar en el mundo para el huilliche. Esta concreción en los cambios topográficos que hoy ha experimentado el roquerío y su entorno lo interpretan algunos huilliches contemporáneos como la voluntad del viejo Huenteao de interrumpir la comunicación. Esteban Aucapán lo narra así

yo alcancé a pasar a esa isla, ahí el mar se juntaba y apartaba, se ponía de vaciante, así pasaba la gente, pero después se encerró, con agua de una tremenda hondura, ahora ya nadie pasa, hay que pasar en bote no 


\section{Escrituras de "encanto" y parlamento en la Poesía Huilliche}

más, él ya no dio camino, se encerró el abuelo Huentiao: (en Gissi Barbieri, 1997) ${ }^{14}$

En este encierro influye la pérdida de la fe en la fuerza de Huenteao y la llegada de huincas y etnoturistas que invaden el entorno, según explica Esteban Aucapan

se encerró el abuelo Huentiao porque llegaron gentes del extranjero, nos molestaron... cuando lo alcancé a conocer yo tenía monte ése, tenía diferentes maderas, tenía murta, pero cuando llegaron los extranjeros rociaron y quemaron ese monte, ahí el abuelo se encerró (en Gissi Barbieri, 1997).

De esta manera, el "encanto" en la oralidad remite a un modo de ser huilliche; representa el ideario de ese comportamiento y se configura como tiempo y espacio sagrados. ${ }^{15} \mathrm{El}$ "encanto" de la oralidad deviene en puente hacia la tradición; puente que se oculta y se cierra en lo topográfico, mientras que en la escritura aparece derrotado ante quienes lleguen a "parlamentar con él” agotados por el viaje de la memoria y pronuncien sus rogativas "con hilachas de un idioma ya intratable”. La petición de bienestar, de la productividad de la tierra y del mar, sólo puede ser invocada en la lengua del "ser encanto", según declaración de uno de nuestros informantes

(Mi padre) entonces ahora empezó a conversar (en) su lengua con el Abuelo Huentiao, pero como uno poco escucha y poco sabe, va escuchando no más po’ y no para de decir nada qué cómo será po’ respondería o no respondería, eso... más no oí -pero entonces pidió todas las comidas de cosecha del mar, que le den, entonces así le dijo que le den todas las cosas del mar. Ahora él, al otro día amaneció...nos

\footnotetext{
${ }^{14}$ Esteban Aucapan evoca un tiempo sagrado o anterior cuando el nexo entre Huenteao y el pueblo huilliche era vigente: "Pero esto... por qué le dicen Pucatrihue... Porque aquí hay un encanto que se llama Abuelito Huentiao, ése está encantado en esa piedra que se ve. Ahí está encantado, así que yo alcancé a pasar pa’l otro lado, se hacía un catrihue así, se apartaba del mar, entonces uno dentra —así como aquí limpio, así en la playa- alcancé a dentrar yo ahí, pero entonces era muy bonito, tenía monte adentro, igual como campo aquí, cuando llegué ahí yo, entonces me dijeron aquí, el Abuelo Huentiao tiene siembra de papas, en el patio, donde está, donde trajina ahí. Así estaban las papitas, mira. Entonces me dijo el finao de mi papi, aquí hay papas — me dijo - y cuando queramos ir, vamos a conseguir papitas pa' semilla. Ya. Entonces yo le dije: “está bien po”, en Nicolás Gissi Barbieri. “Aproximación al conocimiento de la memoria mapuche-huilliche en San Juan de la Costa”. Tesis para optar el título de Antropólogo Social. Santiago: Universidad de Chile. Facultad de Ciencias Sociales. Departamento de Antropología, 1997.

${ }^{15}$ Este tiempo es evocado y reiterado en el rito mediante la abolición del tiempo profano, cotidiano. Cfr. Mircea Eliade. El mito del eterno retorno. Barcelona: Altaza, 1997.
} 


\section{Pilar Álvarez-Santullano - Eduardo Barraza}

levantamos y fuimos al mar, no creerá que todas las cosas del mar (que había). ${ }^{16}$

Los relatos huilliches de "encanto" que abarcan la transformación de seres humanos han sido considerados en estudios antropológicos como soporte de información de la cosmovisión y ritual indígena. Sin embargo, este libro de Huenun, "atestigua un estado de cosas presentes que no se comprende sino a partir de antecedentes históricos" (Mansilla, 1999:13) y testimoniales que el autor va proporcionando en sucesivas notas etimológicas (20-21) epígrafes y dataciones e indicación de fuentes en prosa.

Un mecanismo de resistencia del pueblo huilliche, que lo confirma como colectivo organizado, radica en la conservación de sus autoridades tradicionales, organizadas en la Junta de Caciques, dirigencia estable, institucionalizada y claramente jerarquizada y dirigida por un Apo Üllmen, a la que responden las jurisdicciones de Valdivia, Osorno y Chiloé. Esta Junta de Caciques reconoce su génesis en un "parlamento" o Tratado de Paz celebrado el 8 de septiembre de 1793 entre diversas parcialidades de Río Bueno y de Osorno, luego de sofocado un conato de rebelión en 1792, liderado por el cacique Queipul. ${ }^{17}$ A partir de ese momento, los caciques huilliches desarrollan una estrategia distinta a la del resto de la sociedad mapuche para su sobrevivencia y resistencia frente al conquistador y, más tarde, frente a la autoridad del Estado chileno. Al respecto, la sociedad huilliche (así constituida, política y culturalmente) elabora estrategias discursivas de resistencia ${ }^{18}$

\footnotetext{
${ }^{16}$ El informante continúa expresando la abundancia que les hace llegar Huenteao, como signo de la comunicación que se establece en la lengua propia; vigorosa, no deshilachada: "collof estaba encimita, el mar bajó abajo y el agua pasó así más abajo. Andaba por encima el collof, nosotros (...) ¡Qué de abundancia había, ése, al otro día que vimos nosotros! ¡Qué abundancia, Dios! ¡Qué, si ese día sacamos medio saco de mariscos, mira! Claro sobre nosotros ¡Qué lindura de comida, Dios, señora! Eso lo vine a ver yo. Es muy bonito eso po'. Pero es una cosa del mar. Ese tiempo había... habían erizos — no sé si usted conoce erizos- ése estaba tapado las piedras, coloreaba así... Que uno va a tomar no más, con un palito no más y así vamos sacando... Una abundancia muy grande había anterior, pero ahora, hoy día ya se recogió todo eso ya po', hoy no se ve na' ahora eso, después llegaron los... la gente, mucha gente, personales aquí, así que ya no lo dejan (...) hoy día está escaso eso ya, pero ¿Qué es lo que se ven? Los pescados, sí. Eso sí, no se terminará nunca. Eso sí”. Relato por José Esteban Aucapan Antriao (79 años). Pucatrihue, febrero 20 de 1992. (Recopilado por P. Álvarez-Santullano y C. Contreras).

${ }^{17}$ Rolf Foerster y Sergio Iván Vergara. "Hasta cuando el mundo sea. Los caciques huilliches en el siglo XX” en Pilar Álvarez-Santullano y Amílcar Forno. Fütawillimapu. Osorno: Universidad de Los Lagos, 2001:32. nota 17.

${ }^{18}$ Este tema es desarrollado en la tesis (en ejecución) de Pilar Álvarez-Santullano: De la oralidad a la escritura huilliche: ejercicios contra el evanescimiento y la distancia. Doctorado en Ciencias Humanas, Universidad Austral de Chile.
} 
frente al colonizador, que se textualizan a través de la lengua escrita y de la lengua oral, enviando - cada cierto tiempo- cartas, solicitudes o memoriales, reclamando justicia a las autoridades de turno, autentificando — de paso- - a través de estas cartas su condición de autoridad mapuche-huilliche.

A nuestro juicio, a través de la escritura del "parlamento" de Huenteao en la isla, se evoca la derrota de la tradición oral como estrategia defensiva y de la identidad configurada desde el habla de los kuifikeche y se impone un discurso desacralizado, que desenmascara la miseria del hombre. El discurso oral de Huenteao deviene en un discurso emitido a través de Huenun que, de alguna manera, refuerza la opción de la estrategia escrituraria de la Junta de Caciques, que se inicia con la suscripción de los cacicados al Acta del Tratado de Paz de Las Canoas y el ceremonial público con el cual se recuerda ese pacto. Sólo que en este parlamento, Huenteao prefiere el discurso de un ser vencido cuya miseria es más dolorosa que la de cualquier individuo, porque el vencido más que un individuo es el ser "encanto" que tras la guerra se yergue como última fuerza, memoria y refugio del hombre huilliche. Huenteao es, a fin de cuentas, la esperanza última de sobrevivencia del pueblo huilliche, por eso, su des-encanto, su derrota es también la derrota de su pueblo. Por lo mismo, este discurso de "des-encanto" de Huentao y la materialización de la derrota y la miseria, en el texto de Huenun forma parte de la construcción de lo que hemos denominado el discurso de la conquista en la literatura chilena, hasta ahora circunscrito a la ficcionalización de la conquista en textos literarios e historiográficos de tradición española y chilena. ${ }^{19}$

Conclusiones. "El parlamento de Huenteao en la Isla de Pucatrihue" concluye con la derrota de todo posible vestigio de poder. La voz de Huenteao actúa como contratexto de ese punto cúlmine que sentó las bases de la primera derrota en que devino el pacto desigual con el conquistador a orillas del río Rahue; primer acto, también, en que la dirigencia huilliche transa su oralidad en el mundo de la escritura para reconocer en un texto la superioridad de las armas del Rey y, en consecuencia, el derecho de los españoles a ocupar "la correspondiente extensión de terreno" en las tierras donde se levantó "la ruinada ciudad de Osorno", luego de la victoria que obtuvo Pelantaro sobre sus pobladores en el año 1601. El texto actualiza así, no la ventaja ni la paridad con el otro, sino la derrota reconocida en el "parlamento" llevado a efecto a orillas del Rahue, pero ahora, esta derrota ya no ocurre heroicamente en la guerra, sino en el largo camino de la conquista y de la dominación,

${ }^{19}$ Cfr. Eduardo Barraza. De La Araucana a Butamalón. Valdivia: Universidad Austral de Chile. Anejo $N^{\circ}$ 17/Estudios Filológicos, 2004, donde desarrollamos in extenso esta tesis sobre el discurso de la conquista en la literatura chilena. 
según lo dice hoy este "parlamento" de Huenteao: "Los hombres que ahora veo se hincan en la arena, agotados por el viaje y la memoria".

El Tratado de Paz, nacido históricamente del "parlamento" a orillas del Río de Las Canoas, ha sido siempre invocado en los textos escritos por la dirigencia huilliche como el momento del nacimiento de un pacto ventajoso o en paridad con el invasor, pero, este texto de Huenun invierte la lectura de la dirigencia como momento memorable y beneficioso y lo estipula como signo trágico: el decaimiento e impotencia de sus dioses. El "documento semiamargo" según enuncia el editor del Acta del Tratado de $\mathrm{Paz}^{20}$ se vuelve aquí documento amargo en plenitud y Huenun es quien testimonia la voz de Huenteao para quienes no pueden escucharla, pues hablan ya en un idioma que se extingue como nexo de vida y comunión entre "el ser encanto" y los hombres. Sin embargo, si Huenun incluye la voz vencida, gastada y desacralizada de Huenteao es porque el poeta sí puede oír al kuifikeche en su tragedia (lo que implica que el habla está latente y que el diálogo sigue abierto para quienes lo pueden oír) y puede materializar su voz y apelar a un mejoramiento posible de las condiciones de su pueblo. En este "parlamento de Huenteao" se vitaliza el mito y el rito entre los hombres y los dioses. En este sentido, Huenun reafirma la estrategia escrituraria como recurso de la memoria. El poeta está allí, como Ercilla, para testimoniar. Pero, además, para posibilitar el retorno del mito. En esto, la poesía deviene en mito actualizado, en una textualidad que deja abierto el tiempo circular (por sobre el discurso de la historia): es posible volver a acercarse, porque antes ya hubo otra separación: "el turbio remolino de los tiempos nos aparta nuevamente” y Huenteao, si bien permanece invisible, es eterno.

$$
\begin{array}{r}
\text { Universidad de Los Lagos* } \\
\text { Departamento de Humanidades y Arte } \\
\text { Casilla 933, Osorno (Chile) } \\
\text { palvarez@ulagos.cl } \\
\text { Universidad de Los Lagos** } \\
\text { Casilla 933, Osorno (Chile) } \\
\text { ebarraza@ulagos.cl }
\end{array}
$$

\footnotetext{
${ }^{20}$ Cfr. Parlamento de Paz de 1793. Archivo Museo Histórico. Archivo Emilio Held. Ilustre Municipalidad de Osorno.
} 
Escrituras de “encanto” y parlamento en la Poesía Huilliche

ANEXO

\section{PARLAMENTO DE HUENTEAO EN LA ISLA PUCATRIHUE*}

Si debo decir algo, diré el peso de la piedra en que me han convertido mis paisanos. Mojados por la espuma, lejos de las sementeras y los caminos, nido soy de las gaviotas, el duro territorio de los caracoles y otros animalitos del mar.

Los hombres que ahora veo se hincan en la arena, agotados por el viaje y la memoria. Me ruegan y me hablan con hilachas de un idioma ya intratable, el que un día compartimos. La fuerza de sus sangres ha quedado en el camino. Viejos y temerosos, se entregan a un poder que nunca tuve.

Pronto partirán con sus cosechas de algas y pescado, la pobre ración de sus afanes. El pan y el tabaco que dejan en mis rocas serán para las olas, los ramos de trigo y de flores caerán en las oscuras almas de la profundidad.

El turbio remolino de los tiempos nos aparta nuevamente. De piedra e invisible, eterno en la vejez a la que estoy condenado, hablo solo bajo el cielo del amanecer.

* Huenteao o Huenteyao: espíritu huilliche que habita un islote de rocas en Pucatrihue. Hasta él suelen llegar viajeros y lugareños a pedir permiso para pescar y recolectar lo que deja el oleaje sobre la arena. (Huenun, 1999:43). 
Pilar Álvarez-Santullano - Eduardo Barraza

\section{BIBLIOGRAFÍA}

ÁLVAREZ-SANTULLANO B., Pilar; FORNO S., Amílcar. "La inserción de la lengua mapuche en el currículum de escuelas con educación intercultural: un problema más que metodológico”, en Alpha $\mathrm{N}^{\circ} 26$ (julio 2008):9-28.

ANÓNIMO. La guerra de Chile. Edición crítica de Mario Ferreccio y Raissa Kordic. Santiago: Biblioteca Antigua Chilena, 1986.

ARCHIVO MUSEO HISTÓRICO. Parlamento de Paz de 1793. Archivo Emilio Held. I. Municipalidad de Osorno.

BARRAZA, Eduardo. De La Araucana a Butamalón. Valdivia: Anejo No 17 Estudios Filológicos, 2004.

ELIADE, Mircea. El mito del eterno retorno. Barcelona: Altaza, 1997.

FOERSTER, Rolf; VERGARA, Sergio Iván. "Hasta cuando el mundo sea. Los caciques huilliches en el siglo XX”, en Pilar Álvarez-Santullano y Amílcar Forno. Fütawillimapu. Osorno: Universidad de Los Lagos, 2001, nota 17.

GISSI BARBIERI, Nicolás. “Aproximación al conocimiento de la memoria mapuche-huilliche en San Juan de la Costa”. Tesis para optar el título de Antropólogo Social. Santiago: Universidad de Chile. Facultad de Ciencias Sociales. Departamento de Antropología, 1997.

HUENUN, Jaime. Ceremonias. Santiago: Universidad de Santiago, 1999.

LEÓN, Leonardo. "El parlamento de Tapihue, 1774", en Nütram. Año IX, $N^{\circ}$ 32. Santiago: Rehue, 1993.

LIRA, Máximo R. A orillas del Bío-Bío. (Escenas de la vida araucana). Santiago: Imprenta Independiente, 1870.

MANSILLA, Sergio. "Ceremonias: para alumbrar las viejas sabidurías. Conversación de vivos y difuntos”. Prólogo a Jaime Huenun. Ceremonias. Santiago: Universidad de Santiago (1999):11-14.

MIGNOLO, Walter. La idea de América Latina. La herida colonial y la opción decolonial. Barcelona: Gedisa, 2007.

VILLALOBOS, Sergio. Relaciones fronterizas en La Araucanía. Santiago: Universidad Católica, 1982. 